\title{
Crop protection and environmental health: legacy management and new concepts
}

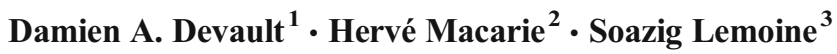

Received: 22 October 2015 / Accepted: 28 October 2015 / Published online: 5 January 2016

(C) Springer-Verlag Berlin Heidelberg 2016

Organic pesticides contributed to the agricultural and sanitary revolution which occurred during the twentieth century, based on the rise of chemical industry. Pesticides allowed to control vectors of disease and to secure quantitatively food supplying.

Involved at global scale, pesticides contributed also to the rise of consumer society: normalising products and discarding products which do not match with aesthetic norm, in disregard of gustative qualities by a more and more urban population. Coupled with mechanisation, pesticides contributed to induce rural depopulation and deeply modified agrarian practices: intensive single cash crop requiring little labour supplanted labour-intensive subsistence and diversified agriculture. Open-field landscapes often attest such evolution.

But pesticides' role predominated directly in human demographic development since the second World War, by counteracting direct or indirect vectors of infectious diseases and allowing settlement in hazardous areas. Longevity and efficiency of pesticide formulations, even in rustic storage and spreading conditions, were exalted characteristics. Some decades later, deleterious effects of pesticides were undoubted: qualities turned in defaults. Global pesticide use induced persistent pollutant stocks in the environment, adsorbed on solid matrices and biomagnified through food web. Residues

Responsible editor: Philippe Garrigues

Damien A. Devault

damien.devault@martinique.univ-ag.fr

1 Université Paris Sud, Faculté de Pharmacie, UMR 8079, CNRS, AgroParisTech, France

2 Aix Marseille Université, CNRS, IRD, Avignon Université, IMBE, UMR 7263 - IRD 237, 13397, Marseille, France

3 UMR BOREA, CNRS-7208, IRD-207, MNHN, UPMC, UCBN, Université des Antilles, DYNECAR, Campus de Fouillole, BP 592, 97159, Pointe-à-Pitre, France of pesticides conceived a long time ago and whose use is discontinued are still quantified in the environment. They are a part of the concerning heritage for current and future generations - another part of the legacy being consumer appetence for artful normalised products.

Environmental monitoring led to inform about discontinued pesticide residue content, which is cumulated with more recent pesticides and with the pesticides currently used. Metrological development, leading to lower quantification and detection limits for pesticides, provides abundant information about environmental contamination and increases the need of prioritisation for such molecules, considering their impact for human and environmental health. The anteriority of works for elder pesticides could paradoxically induce their overrepresentation compared to recent pesticides for which scientific research lacks of support for reaching the same level of knowledge. But elder pesticides like DDT or chlordecone appeal to management solutions, because their persistence and ubiquity obstruct definitive remediation.

However, such statement is mired in cognitive bias too because pesticide uses have alternatives, as for crops (agroecological above all) as for urban area maintenance (mainly mechanistic). Indeed, if the agro-industrial model grows because of the increase of the human population food needs, the agro-ecological alternative is recognised worldwide and grows faster. Agro-ecology bases on crop rotation and promotes soft agricultural practices like biological auxiliaries.

Since 1977, francophone researchers working on pesticides get together for the annual colloquium of the "Groupe Français des Pesticides" association (GFP). In 2014, the 44th colloquium was held in Martinique (French West Indies), from May 26 to 29. GFP is an association aiming to gather scientific community coming both from the private and public sector, involved in the study of pesticides whatever the disciplines, leading to transversal views and then innovative initiatives. Scientists from French (including overseas) and 
foreign universities but also from French public research institutes (BRGM, CNRS, CEA, Cirad, IFREMER, INRA, INSERM, IRD, IRSTEA) and from the industry came for exchanging their views and respective expertise on scientific news, thanks to grants from the Martinique Watershed Office (ODE 972), the Regional Health Agency (ARS 972), the "Ecophyto" French plan (locally applied by the Food, Agriculture and Forest Direction-DAAF 972-and the Council for Agriculture-CA 972), the Environment, landuse planning and housing direction (DEAL 972), the Scientific Department of the Martinique campus of the French West Indies and Guyana University, the Fort-deFrance conurbation community (CACEM) and ThermoFisher Scientific. The international scale of the event was supported by Institut de Recherche pour le Développement (IRD - French institute for scientific research in favour of South development) and especially its representation for West Indies, and by the office for West Indies of AUF, the Academic Association of French-speaking countries: IRD and AUF supported scientists from Latin America, Caribbean area and Africa.

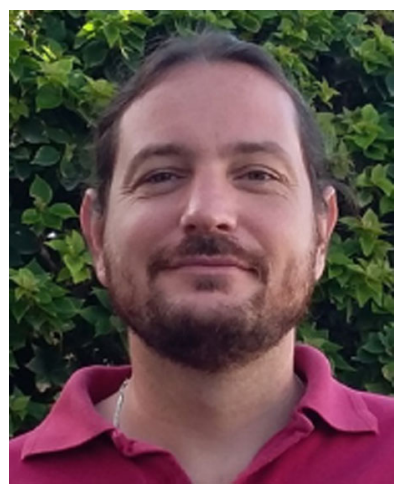

Damien A. Devault He is a research officer at the Université Paris-Sud, ESE lab, located in French West Indies. He has been successively in position at Paris and Martinique centres of the National Research Institute of Science and Technology for Environment and Agriculture (IRSTEA), then at the University of French West Indies, AIHP-GEODE lab. His research interest focuses on the fate of organic micropollutants in the aquatic environment, especially where standard conditions (oxygen saturation, neutral $\mathrm{pH}$, standard redox...) are not reached: wastewater, sludge, but mainly sediment under early diagenesis influence. He previously led the first study crossing in situ early diagenesis indicators and pesticide content in sediment cores which highlighted the massive storage of pesticides in sediment and the most efficient dam reservoir configuration to promote their natural degradation. Due to the importance of these findings, the Toulouse Science Academy awarded him the Edouard Maurel price for public health (2008). Damien A. Devault is also involved in the study of the monitoring of solid matrixes and especially aims to cross the benthic condition for enhancing the use of passive samplers. Organic micropollutants presently studied by Damien Devault are pesticides, pharmaceutical residues and illicit drugs. Illicit drug studies led him to be appointed as French representative for e-COST "SCORE" for the evaluation of population health based on chemical tracers in water. He is the assistant treasurer of the "Groupe Français des Pesticides", the association in charge of the organisation of the annual colloquium gathering the community of French-speaking scientists working on pesticide issues.

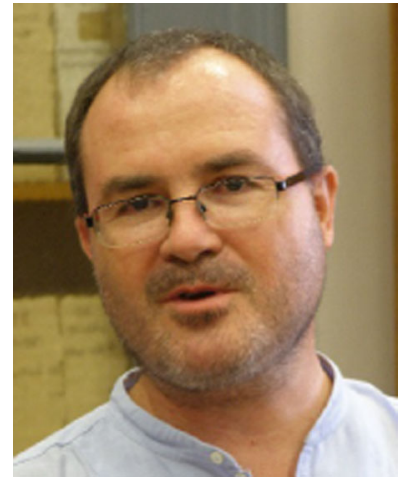

Hervé Macarie He is a research officer at the Research Institute for Development (IRD exORSTOM). In this position since October 1994, he has developed research on the technological and the microbiological aspects (taxonomy and ecology) of the anaerobic treatment of industrial wastewater and he has both an experience at lab and full scale (up to reactors of $20,000 \mathrm{~m}^{3}$ ). One of his main interests has been for the anaerobic degradation of xenobiotic compounds such as terephthalic acid and pentachlorophenol and the development of synchronous anaerobic/aerobic systems to achieve the full mineralization of this last compound. Since 2008, his research has been almost entirely focused on the microbial degradation of chlordecone, an organochlorine insecticide classified as POP that was once used against the banana black weevils and that is now responsible, 20 years after the ban of its utilisation, of a health, environmental, economic and social crisis in the French West Indies islands of Guadeloupe and Martinique. Along his career, he has been successively in position in Canada (postdoctoral fellow, BRI, NRC, 1992-1994), Mexico (visiting Professor, UAM-Iztapalapa, 1995-2000), continental France (Aix Marseille University, 2001-2010) and Martinique (CAEC, 2011-2014). Since 2015, he is back to Aix Marseille University and Mediterranean Institute for Marine and Continental Biodiversity and Ecology (IMBE) where he will pursue his research on the theoretical and experimental aspects of chlordecone degradation with the objective to understand the factors limiting its natural attenuation and the possibility to manipulate them in order to propose a bioremediation process to decontaminate the polluted soils.

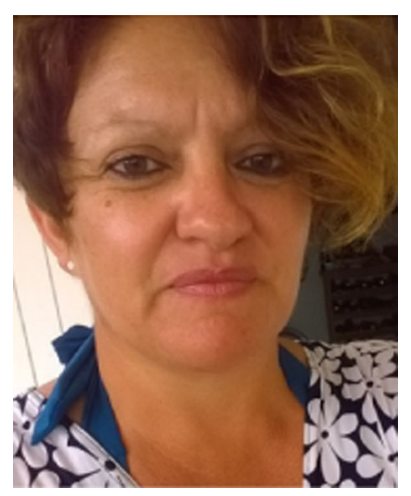

Soazig Lemoine She is associate Professor at the University of French West Indies (Guadeloupe campus) since 2001. She has been involved for about 15 years in the study of the effects of pollutants like heavy metals and pesticides in aquatic invertebrates particularly mollusc and crustacean. Her work has been focused on physiological and gene expression changes induced by pollutants, and she has developed biomarkers of oxidative stress, genotoxicity and detoxification system in tropical aquatic organism. In the past 6 years, her research has been mostly dedicated to study the impact of chlordecone on the same group of aquatic invertebrates. Chlordecone is a persistent organochlorine pesticide widely used between 1972 and 1993 in the French West Indies to control the root borer in banana fields. Chlordecone use resulted in long-term pollution of soils and contamination of waters and of aquatic organisms. Dr. Lemoine has been involved in several French national research programmes in ecotoxicology, and she has been coordinating the MACHLOMA project founded by ANR, the French National Research Agency, about chlordecone. 